\title{
The influence of exercise on growth hormone and testosterone in prepubertal and early-pubertal boys
}

\author{
Charilaos Tsolakis ${ }^{1}$, Paraskevi Xekouki ${ }^{2}$, Socratis Kaloupsis ${ }^{1}$, Dimitrios Karas ${ }^{1}$, \\ Dimosthenis Messinis ${ }^{1}$, George Vagenas ${ }^{1}$, Athanasios Dessypris ${ }^{3}$
}

${ }^{1}$ Department of Physical Education and Sports Science, Athens University, ${ }^{2}$ Endocrine unit, First Dept of Pediatrics Athens University School of Medicine, ${ }^{3}$ Department of Biochemistry and Molecular Biology, Athens University, School of Biology, Athens, Greece

\begin{abstract}
The purpose of this study was two fold a) to determine the levels of hormonal parameters which are related to growth and sexual maturation (T, SHBG, FAI, GH) in 66 pre-pubertal and early-pubertal boys (11-13 years old) who systematically engage in individual and team sports activities of endurance, strength, speed and skill, respectively, and b) to investigate the effect of two different forms of exercise namely aerobic (AG) and weight training (WG) on androgen levels in 19 sedentary pre-pubertal boys. The control groups (CG) consisted of boys of the same age who attended only the school physical education programmes. The individuals included in the study participated voluntarily after their parents had been informed and had given their written consent. Hormonal concentrations were determined using radioimmunoassay and immunoradiometric assays. No differences were observed among the various athletes' groups as regards Tanner stages, height and weight. The mean $T$ and $F A I$ values of the control group did not differ from those of the corresponding athletes group. Significant differences were observed among the groups regarding BMI, \% body fat, T, SHBG, FAI and GH $(p<0.05)$. T and FAI values in the WG group were significantly higher than the corresponding concentrations: a) in the $A G$ group by 338 and $609 \%, p<0.05$ and $b$ ) in the control group CG by 91 and $96 \%, p<0.05$, respectively. The hormonal differences detected among the various groups of athletes must be attributed as much to the type of physical exercise and to developmental factors as to the selection criteria used for the different athletic talents. The importance of the specificity of training stimulus in the hormonal adaptations of pre-pubertal sedentary subjects was demonstrated.
\end{abstract}

Key words: sports, Testosterone, GH, physiological adaptations.

\section{INTRODUCTION}

The huge growth in the popularity of sports among

Address correspondence and requests for reprints to: Tsolakis Charilaos Ph.D,6 Kotsika str., e-mail: tsolakis@phed.uoa.gr

Received 16-12-02, Revised 21-02-03, Accepted 13-03-03 youth over the last two decades has led to children's participation in them at ever younger ages, and in training programmes of increased intensity and prolonged duration, resulting in various effects on the rate of physical growth and maturity ${ }^{1,2}$.

The athletic talent selection is made according to 
hereditary, physical and functional criteria, and this, at the time when the body is undergoing the complex changes of somatic growth and sexual maturation ${ }^{3}$, complicates the interpretation of exercise - related adaptations.

Development in boys is mainly dependent on the interaction of the progressive increase in androgens and growth hormone, causing characteristic changes in body constitution, distribution of fat tissue and muscular strength ${ }^{4}$.

The effect of intense training on the pituitary axis of adults has been thoroughly studied ${ }^{5,6}$ and reflects the biological and psychological stress related to exercise. The biological responses to intense training are related to the metabolic and neuromuscular features of the exercise ${ }^{7}$, with strength training clearly causing adaptations different from other forms of exercise such as aerobic activities ${ }^{8}$. There are few data however for athletes in the pre-pubertal period ${ }^{9-11}$, while the effects of different forms of exercise on sedentary pre-pubertal and pubertal individuals are conflicting. Specifically, $\mathrm{T}$ and FAI mean values have been reported to increase $e^{9-11}$, remain stable ${ }^{12-14}$ or decrease ${ }^{15}$, following acute intense exercise or two-month to one-year training.

The aim of this study was to compare: a) the levels of hormonal parameters which are related to growth and maturity [Testosterone ( $\mathrm{T})$, sex hormone binding globulin (SHBG), free androgen index (FAI), growth hormone $(\mathrm{GH})$ ] in pre-pubertal and early-pubertal boys who systematically participate in individual and team sports activities of endurance, strength, speed and skill, and b) the effect of two different forms of exercise (aerobic and weight training) on androgens in sedentary pre-pubertal boys since the results of studies on well trained athletes cannot be extended to other population groups ${ }^{16}$.

\section{SUBJECTS AND METHODS}

\section{a) Athletes}

Eighty (80) children belonging to 8 groups were included in the analysis: 11 runners, 11 swimmers, 9 basketball players, 9 handball players, 10 rowers, 8 weight-lifters and 8 fencers. Their age ranged from 11 to 13 years. The control group consisted of 14 boys of the same age range. The athletes had been selected via school and national development sport talent programmes under the minimum criteria of 8 months of regular athletic training, appropriately designed for the age group, and were subjected to moderate intensity training programmes at least 3 times a week, enabling them to learn the basic kinetic patterns of each sport. The boys who participated in the control group were screened from a large number of schoolboys on the maximum criteria of regularly attending standard school physical exercise classes. Anthropometric characteristics of all subjects are presented in Table 1.

\section{b) Sedentary boys}

Twenty nine boys are included in this group. Nine boys aged 11-13 yrs were subjected to a two-month regular weight training programme, 3 times a week,

Table 1. Anthropometric characteristics of experimental and control groups (mean $\pm \mathrm{SD}$ )

\begin{tabular}{|c|c|c|c|c|c|c|}
\hline & Age (years) & Height (SDS) & Weight (SDS) & $\%$ fat & BMI (SDS) & Tanner stages \\
\hline 1. Handball & $12.63 \pm 0.36$ & $0.52 \pm 0.70$ & $-0.15 \pm 0.74$ & $11.20 \pm 3.01$ & $-0.74 \pm 0.67$ & $2.77 \pm 0.66$ \\
\hline 2. Rowing & $13.06 \pm 0.12$ & $1.18 \pm 1.07$ & $0.93 \pm 1.01$ & $20.08 \pm 4.61$ & $0.03 \pm 0.89$ & $2.8 \pm 0.42$ \\
\hline 3. Running & $12.03 \pm 0.92$ & $0.03 \pm 0.78$ & $-0.55 \pm 0.61$ & $7.93 \pm 3.19$ & $-0.77 \pm 0.81$ & $2.27 \pm 0.78$ \\
\hline 4. Basketball & $13.02 \pm 0.64$ & $0.91 \pm 1.18$ & $-0.07 \pm 0.95$ & $7.25 \pm 1.46$ & $-1.04 \pm 0.63$ & $2.77 \pm 0.44$ \\
\hline 5. Swimming & $11.15 \pm 1.11$ & $0.77 \pm 1.39$ & $1.54 \pm 0.86$ & $9.32 \pm 2.99$ & $-0.79 \pm 0.86$ & $2.40 \pm 0.66$ \\
\hline 6. Weight-lifting & $11.15 \pm 1.11$ & $0.71 \pm 1.74$ & $1.12 \pm 1.57$ & $14.47 \pm 5.96$ & $0.91 \pm 1.13$ & $2.25 \pm 0.88$ \\
\hline 7. Fencing & $12.39 \pm 1.30$ & $0.47 \pm 0.55$ & $0.29 \pm 0.91$ & $15.27 \pm 11.63$ & $-0.20 \pm 1.38$ & $2.25 \pm 0.70$ \\
\hline 8. Control & $12.85 \pm 0.36$ & $-0.03 \pm 0.91$ & $0.02 \pm 1.46$ & $18.85 \pm 6.14$ & $-0.21 \pm 1.48$ & $2.57 \pm 0.51$ \\
\hline $\begin{array}{l}\text { Post hoc comparison*. } \\
(\mathrm{p}<0.05)\end{array}$ & 6 vs $1,2,4,8$ & NS & NS & $\begin{array}{c}2 \text { vs } 1,3,4,5 \\
6 \text { vs } 3,4 \\
8 \text { vs } 3,4,7\end{array}$ & 7 vs $4,5,6$ & NS \\
\hline
\end{tabular}

*Bonferroni adjustments, SDS: standard deviation score 
comprising 6 exercises of the trunk and the upper limbs, $3 \times 10 \mathrm{RM}^{17}$, while 10 peers of the same characteristics were subjected to a two-month aerobic training programme on the treadmill, 3 times a week at $70 \%$ PWC170 for 45 minutes ${ }^{13}$. None of these subjects had previously been engaged in sports. Their control group consisted of 10 boys of the same age, who were not subjected to any kind of intense exercise for the duration of the programme. The anthropometric characteristics of the entire group are given in Table 2.

All subjects in the study participated voluntarily after their parents had been informed and had given their written consent. Their pubertal growth was determined according to Tanner criteria ${ }^{18}$, and the subjects were medically tested prior to their participation in the study so that endocrinological abnormalities, metabolic diseases or other adverse factors would be excluded.

The School of Biology, Department of Biochemistry and the Sports Medicine and Biology Department of Physical Activity of Athens University, approved the study.

Anthropometry: Subjects' standing height (Ht) was measured with a portable Harpender stadiometer to the nearest $0.1 \mathrm{~cm}$, and the weight $(\mathrm{Wt})$ was determined using a digital weight scale (Seca 707) with a precision of $0.1 \mathrm{kgr}$. Skinfolds were taken with a Harpenden skinfold caliper and \% body fat was estimated using Slaughter's equation ${ }^{19}$. Fat estimation from skinfolds gives body composition results comparable to those obtained from DEXA ${ }^{20}$. All anthropometric and body composition raw data were measured by one investigator with a previously controlled test retest reliability of $r \geq 0.92$.

Blood Tests: After 2 days of rest and 12 hours of fasting, approximately $10 \mathrm{~mL}$ of blood was drawn from the antecubital forearm vein using a gauge needle $21 \mathrm{G}$ x $1^{1 / 2 \% /}$ vacutainer set up between 08.30-09.00 hours. The blood was allowed to clot at room temperature $\left(22^{\circ} \mathrm{C}\right)$ and the serum was separated by centrifugation at $3000 \mathrm{rpm}$ for $15 \mathrm{~min}$ and then stored at $-30^{\circ} \mathrm{C}$ until analyzed (within 30 days). All blood samples were determined in duplicate

Hormone assays: GH concentrations were determined using an ELSA-HGH solid phase two-site immunoradiometric assay (Cis bio international, ORIS Group, France). The sensitivity was $0.04 \mathrm{ng} / \mathrm{mL}$. The intra- and inter-assay CVs were 2.4, 2.8, 2.8, 2.3 and 4.2, 3.2, 4.4, 4.0, for concentrations of 3.5, 7.3, 17, 47.4, and 3.3, 7.1, 16.4, $45.4 \mathrm{ng} / \mathrm{mL}$, respectively. There was no cross-reaction with LH, FSH, HCG, TSH or Prolactin.

Testosterone concentrations were determined using a Gammacoat $\left({ }^{125} \mathrm{I}\right)$ Testosterone radioimmunoassay kit (Dia Sorin, USA). The sensitivity was 0.059 $\mathrm{ng} / \mathrm{mL}$ The intra- and inter-assay CVs (\%) were 6.2, $6.7,8.6$ and $6.9,7.71,13.6$, respectively. The cross reactivity with dihydrotestosterone, androstendione, epitestosterone and cortisol was 3.8, 0.8, 0.4, 0.02, respectively.

SHBG concentrations were determined using an SHBG two-site immunoradiometric assay (DSL Inc, USA). The sensitivity was $3 \mathrm{nmol} / \mathrm{L}$. The intra- and inter-assay CVs were 3.7, 1.1, 3.4 and 11.5, 10.3, 8.7 for doses of 27, 92, 119 and 26, 87, $115 \mathrm{nmol} / \mathrm{L}$, respectively. No human serum protein is known to crossreact with the antibodies employed in the DSL SHBG IRMA system.

The Free Androgen Index (FAI) was calculated using the formula:

$$
\mathrm{FAI}=\frac{\text { concentration of total } \mathrm{T}(\mathrm{nmol} / \mathrm{L})}{\text { concentration SHBG }(\mathrm{nmol} / \mathrm{L})} \times 100^{21}
$$

Table 2. Anthropometric characteristics of experimental (AG, WG) and control groups (CG), (mean \pm SD)

\begin{tabular}{lcccc}
\hline & AG: & $\begin{array}{c}\text { WG: } \\
\text { aerobic training group }\end{array}$ & resistance training group & CG: \\
control group & $12 \pm 0.81$ & F Sign. \\
\hline Age & $11.7 \pm 1.33$ & $11.77 \pm 0.83$ & $2.15 \pm 0.88$ & NS \\
Tanner Stage & $2.1 \pm 0.78$ & $2.26 \pm 0.41$ & $157.2 \pm 6.83$ & NS \\
Height & $153.5 \pm 7.3$ & $154.7 \pm 6.74$ & $47.24 \pm 9.16$ & NS \\
Weight & $45.3 \pm 9.36$ & $41.26 \pm 9.41$ & $14.61 \pm 3.24$ & NS \\
\%fat & $16.57 \pm 7.16$ & $12.94 \pm 2.72$ & \\
\hline
\end{tabular}




\section{Statistical analysis}

Differences between groups were determined using ANOVA, followed by Bonferroni post hoc comparisons. For all univariate correlational analysis, Pearson's coefficient was calculated. Height, BMI and weight were transformed into standard deviation scores (SDS) according to the following equation: $\mathrm{SDS}=($ actual value-mean $) / \mathrm{SD}$

The data in the tables are presented as mean \pm SD . For each analysis statistical significance was tested at the $\alpha=0.05$ probability level.

\section{RESULTS}

\section{a) Athletes}

No significant differences were observed among the groups with regards to Tanner stages, weight and height. Significant differences were observed among the groups regarding BMI and \% body fat, T, SHBG, FAI and GH ( $p<0.05$, Tables 1, 3 and Figures 1-6). Specifically, fencers' BMI was greater than that of basketball players, swimmers and smaller than that of weight-lifters. Rowers had the highest \%fat values and basketball players the lowest among the different ath-

Table 3. Hormonal concentrations of experimental and control groups (mean $\pm \mathrm{SD})$

\begin{tabular}{lcccc}
\hline & T $(\mathbf{n m o l} / \mathbf{L})$ & SHBG $(\mathbf{n m o l} / \mathbf{L})$ & FAI & GH $(\mathbf{n g} / \mathbf{m L})$ \\
\hline 1. Handball & $13.75 \pm 10.19$ & $62.84 \pm 30.14$ & $29.96 \pm 32.29$ & $16.68 \pm 24.86$ \\
2. Rowing & $17.19 \pm 9.21$ & $35.2 \pm 17.97$ & $62.32 \pm 39.42$ & $5.58 \pm 5.96$ \\
3. Running & $11.37 \pm 11.18$ & $143.27 \pm 35.16$ & $12.99 \pm 16.34$ & $3.07 \pm 6.97$ \\
4. Basketball & $9.22 \pm 7.33$ & $140.33 \pm 85.47$ & $10.18 \pm 8.09$ & $2.34 \pm 3.54$ \\
5. Swimming & $5.66 \pm 5.31$ & $128.09 \pm 59.01$ & $6.65 \pm 8.15$ & $0.87 \pm 0.71$ \\
6. Weight-lifting & $3.003 \pm 3.47$ & $131.82 \pm 76.65$ & $4.05 \pm 5.91$ & $0.23 \pm 0.25$ \\
7. Fencing & $7.11 \pm 5.65$ & $151 \pm 74.37$ & $5.56 \pm 4.82$ & $3.92 \pm 6.25$ \\
8. Control & $5.53 \pm 4.90$ & $39.92 \pm 9.21$ & $15.16 \pm 13.31$ & $6.34 \pm 5.79$ \\
Post hoc comparison* $(\mathrm{p}<0.05)$ & $2 \mathrm{vs} 6$ & $1 \mathrm{vs} \mathrm{3,4,5,6,7}$ & $1 \mathrm{vs} 6$ & $6 \mathrm{vs} 1,2,3,8$ \\
& & $2 \mathrm{vs} \mathrm{3,4,5,6,7}$ & $2 \mathrm{vs} \mathrm{3,5,6,7}$ & $5 \mathrm{vs} 8$ \\
\hline
\end{tabular}

*Bonferroni adjustments, T: Testosterone, SHBG: Sex hormone binding globulin, FAI: free androgen index, GH: growth hormone

BMI (sds)

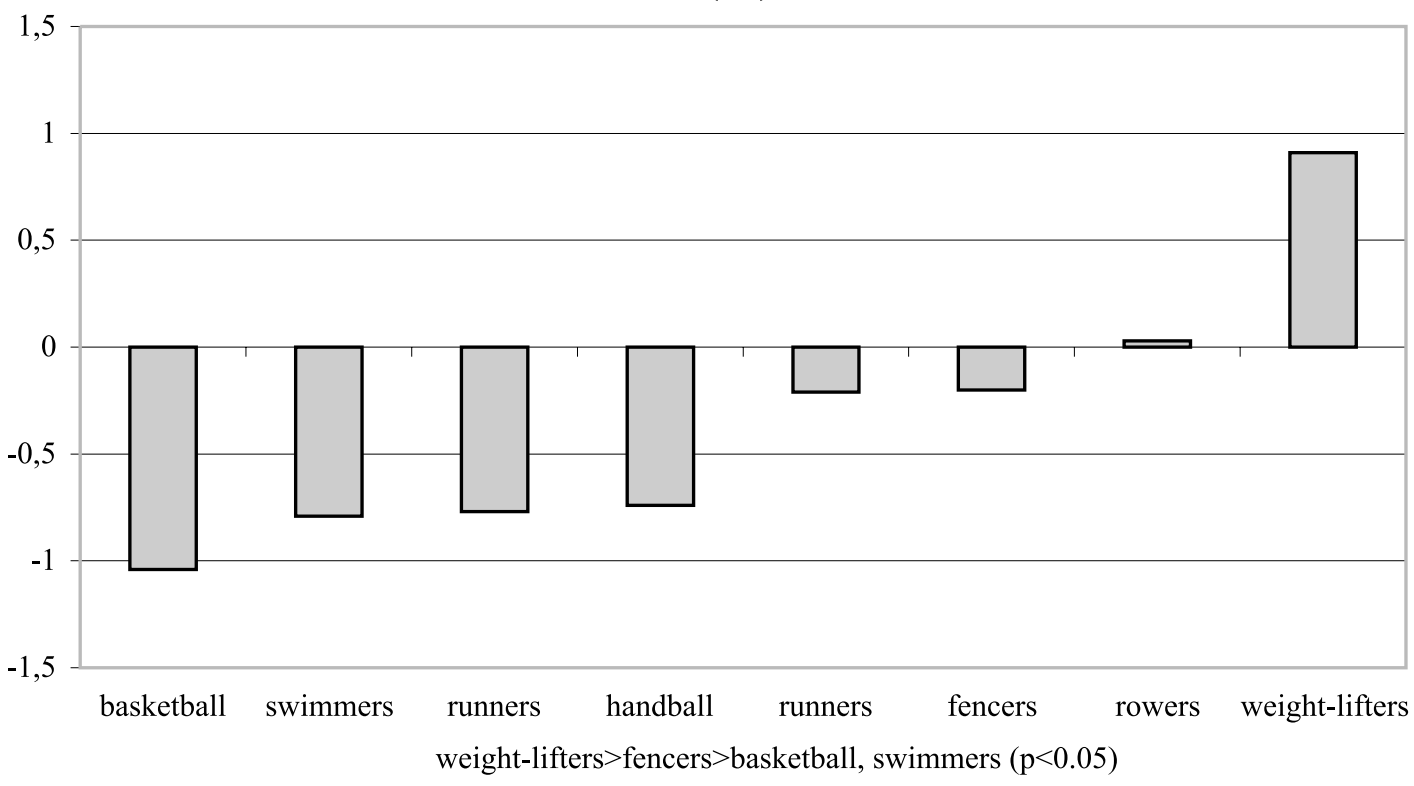

Figure 1. BMI of experimental and control groups. 


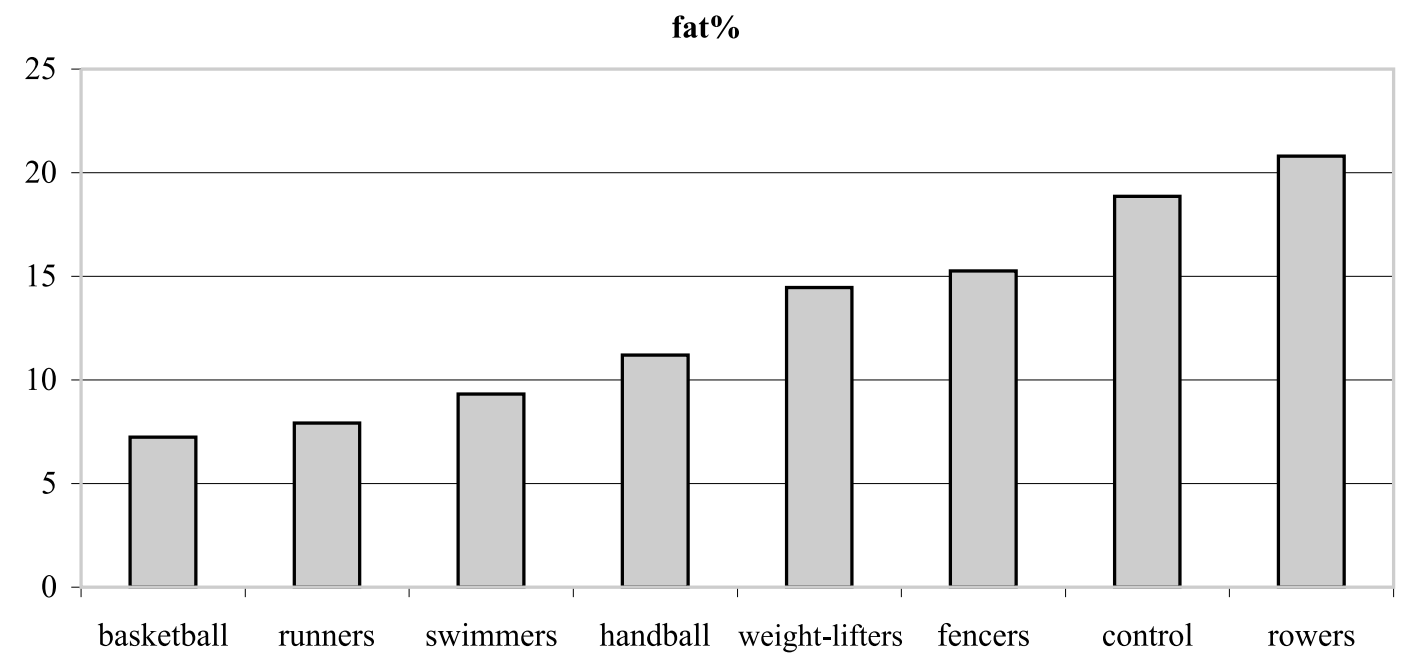

rowers $>$ handball,runners, basketball,swimmers. Swimmers $>$ runners, basketball. Control $>$ runners, basketball, fencers $(\mathrm{p}<0.05)$

Figure 2. \%fat of experimental and control groups.

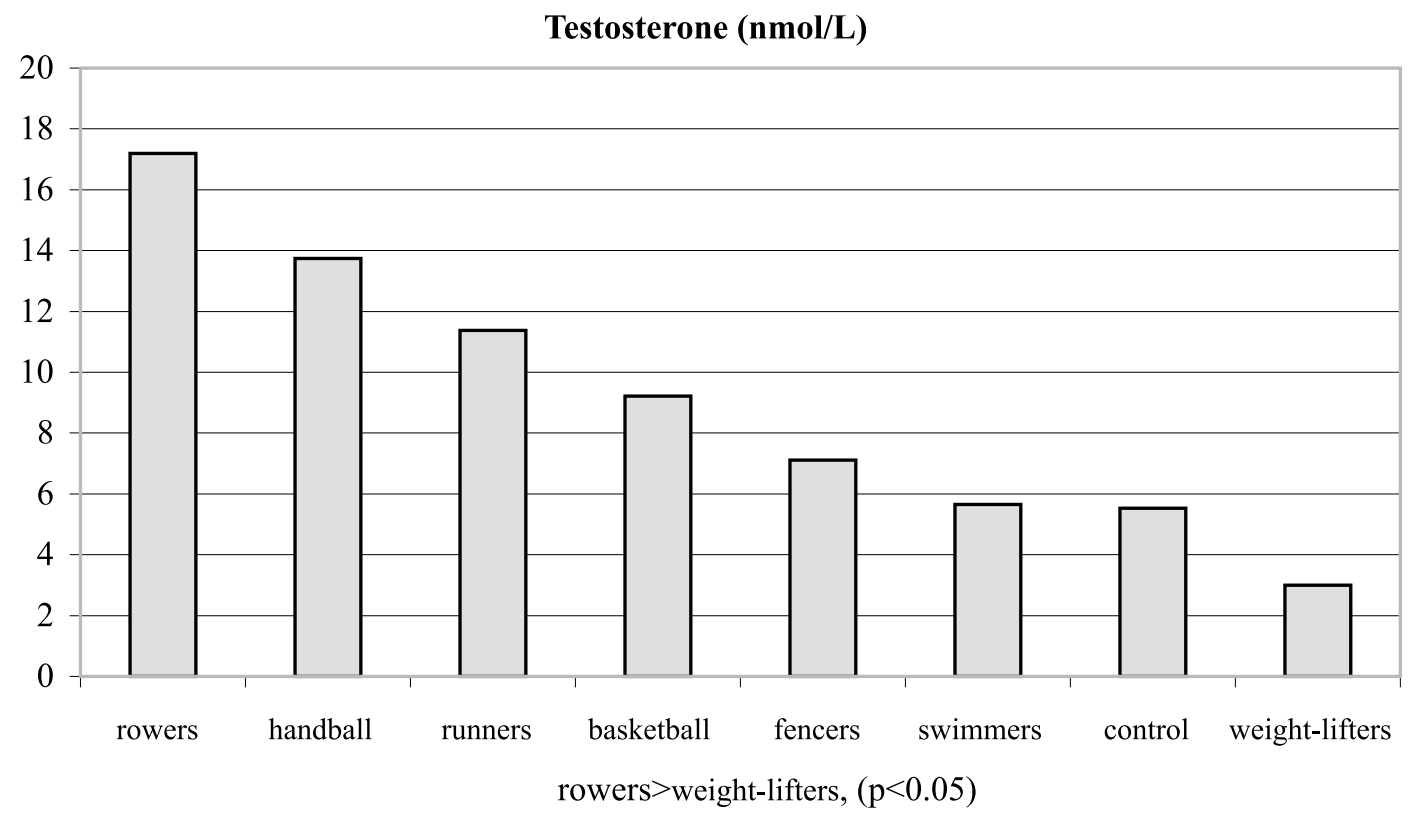

Figure 3. Testosterone concentrations of experimental and control groups.

letes groups. The control group had more \%fat than runners, basketball players and fencers. Rowers had the highest mean $\mathrm{T}$ and FAI values, and the weightlifters the lowest, and these two hormonal parameters were significantly different between these two groups. Additionally, rowers had the lowest SHBG mean values which were significantly different than those of runners, basketball players, swimmers, weight- lifters and fencers. The SHBG mean values of runners, basketball players, swimmers, and weight-lifters, were significantly greater than those of controls. The GH mean values were highest in the handball players and lowest in the weight-lifters. The values in the weight lifters were significantly lower than in handball players, rowers, runners and controls; while the values in swimmers were lower only in comparison to 


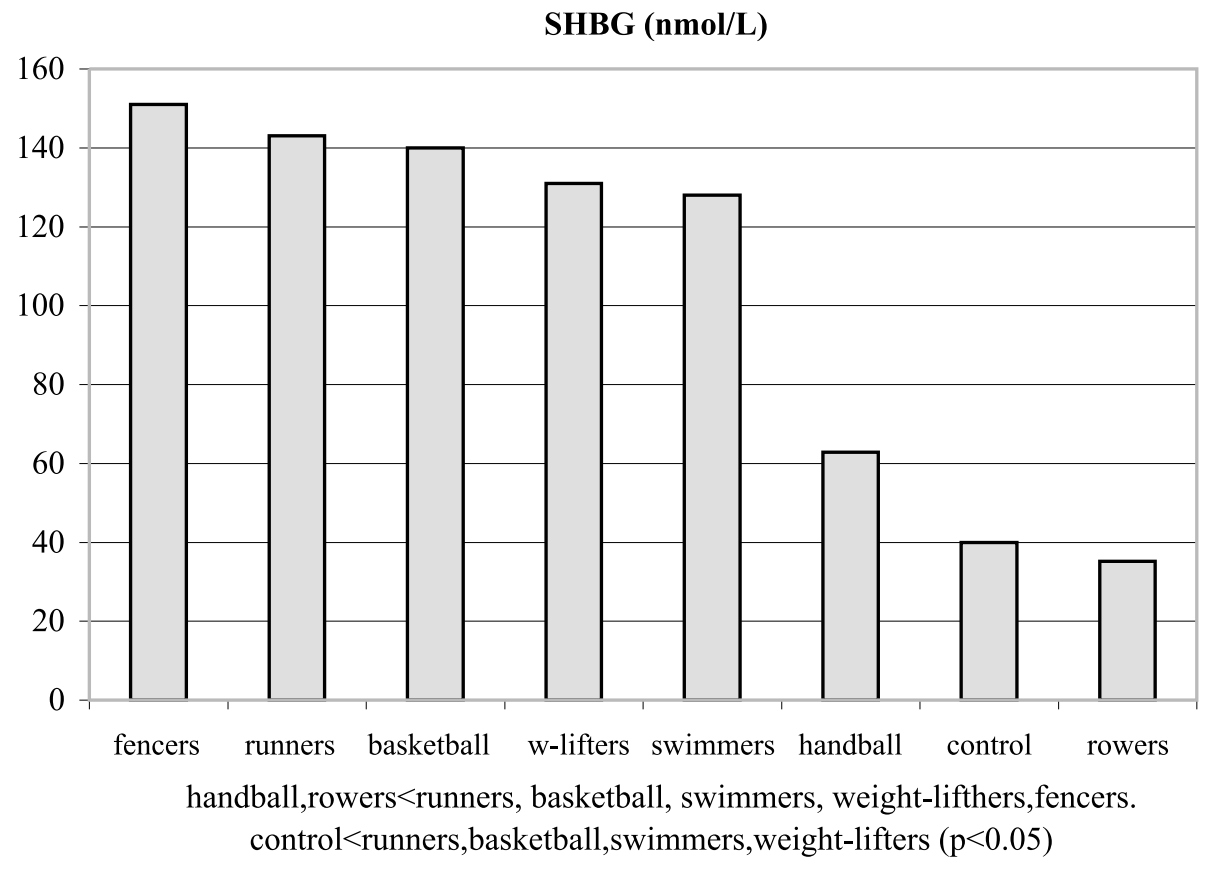

Figure 4. SHBG concentrations of experimental and control groups.

FAI

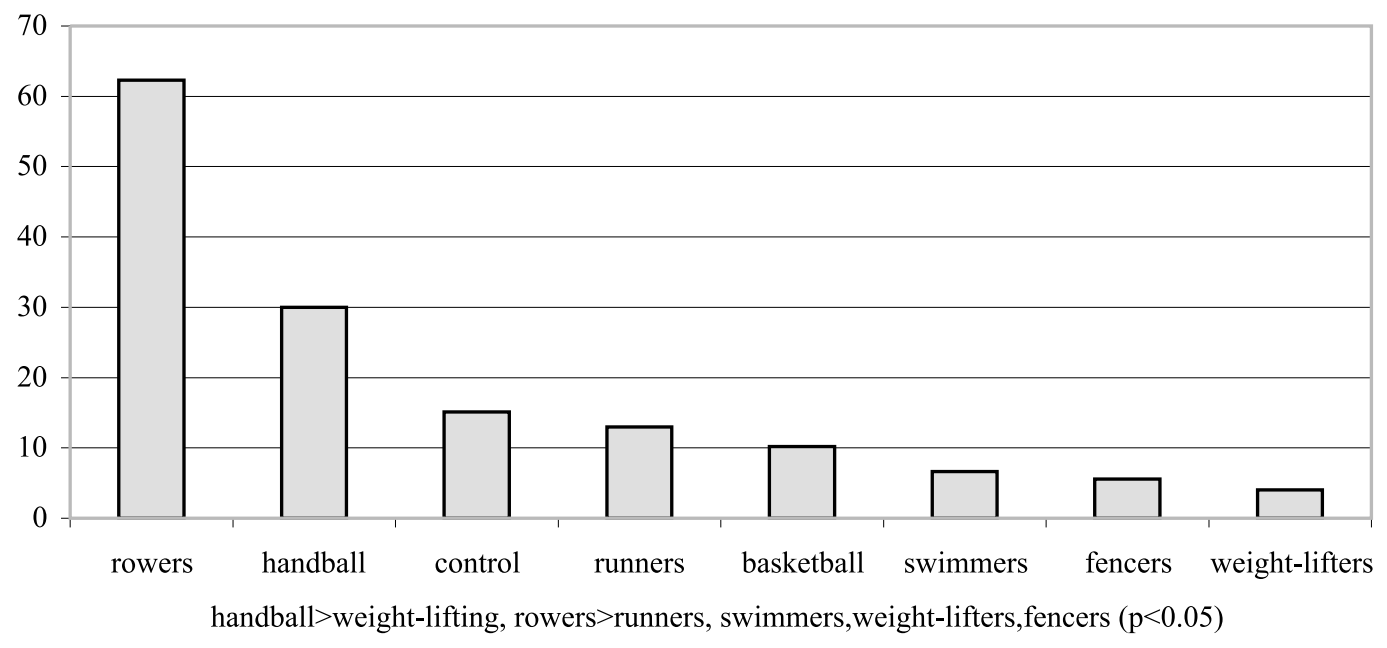

Figure 5. FAI mean values of experimental and control groups.

controls.

The mean $\mathrm{T}$ and FAI values of the control group did not differ significantly from those of the athletes groups (Table 3). Significant differences, however, were observed among the groups: a) in $\mathrm{T}$ when age was used as a covariance $(\mathrm{F}=5.72, \mathrm{p}<0.05)$ and $\mathrm{b})$ in SHBG when age, developmental stages and BMI were also used as covariances with $\mathrm{F}$ rising from 19.31 to
40.25, p<0.000 (Table 4).

The mean values of T, SHBG and FAI of the total athletes group were correlated with age, height, body weight and Tanner stages with minimum value of $r$ 0.370 and maximum $0.532,(p<0.05)$. The values of GH were correlated with Tanner stages, $\mathrm{T}$ and FAI with minimum value of $\mathrm{r} 0.259$ and maximum 0.532 , $(p<0.05)$. No correlation was observed among the hor- 


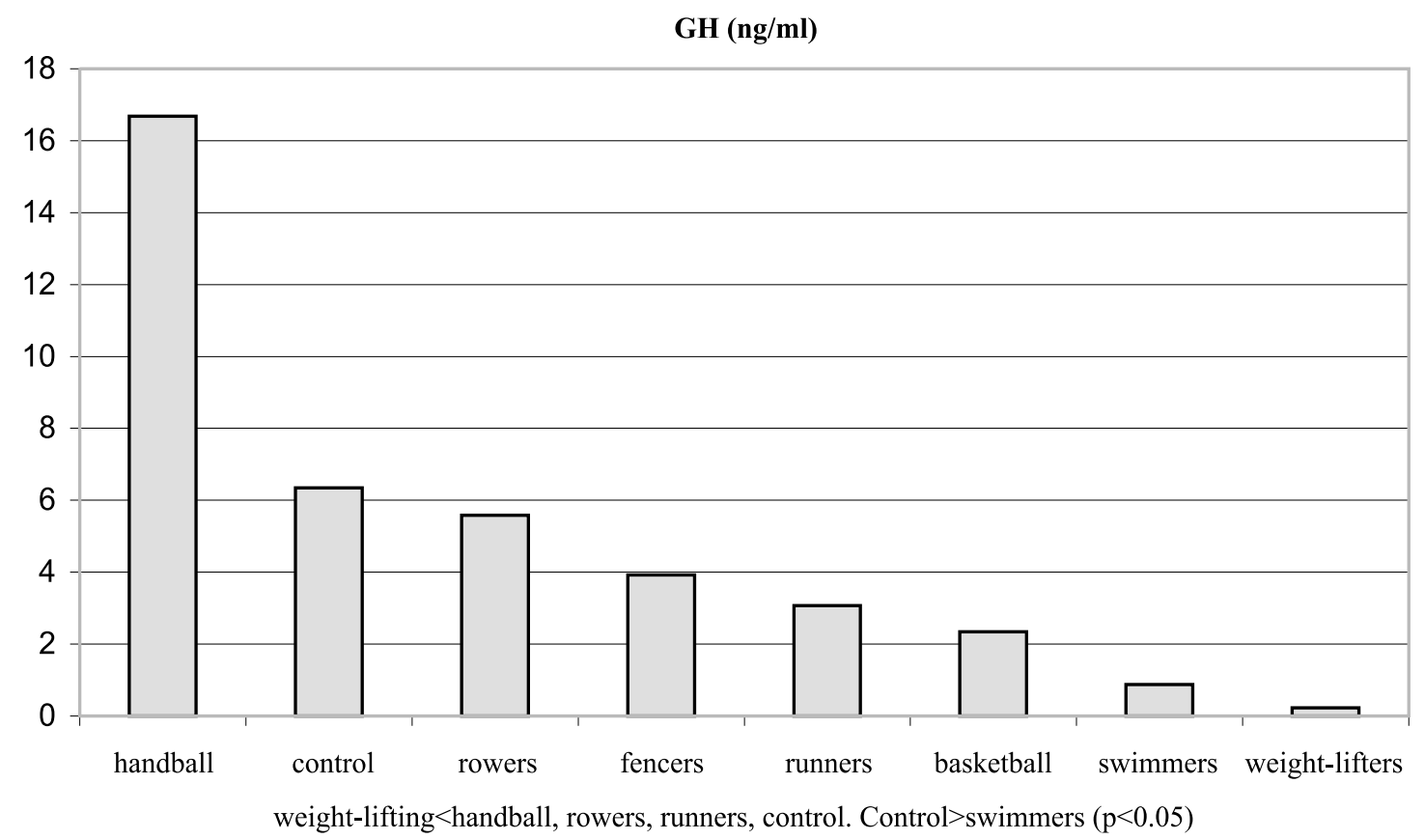

Figure 6. GH concentrations of experimental and control groups.

Table 4. Differences between experimental groups when age, Tanner stages and BMI were taken into consideration as covariates

\begin{tabular}{lcccc}
\hline Covariates & T $(\mathbf{n m o l} / \mathbf{L})$ & SHBG $(\mathbf{n m o l} / \mathbf{L})$ & FAI & GH $(\mathbf{n g} / \mathbf{m L})$ \\
\hline Age & $5.72^{*}$ & $19.31^{* * *}$ & NS & NS \\
Tanner & NS & $40.25^{* * *}$ & NS & NS \\
BMI & NS & $22.75^{* * *}$ & NS & NS
\end{tabular}

Significant $\mathrm{F}$ values: ${ }^{*} \mathrm{p}<0.05,{ }^{* * *} \mathrm{p}<0.001, \mathrm{NS} \mathrm{p}>0.05$

monal parameters, age, pubertal stages and anthropometric characteristics in the control group, while $\mathrm{T}$ was correlated with $\mathrm{GH}$ and FAI with minimum value of r 0.537 and maximum $0.931,(\mathrm{p}<0.05)$, respectively.

\section{b) Sedentary boys}

The mean differences between the beginning and the end of the experimental period in T and FAI values of the WG group were significantly higher than the corresponding differences: a) of the AG group by 338 and $609 \%, \mathrm{p}<0.05$ and b) the CG group by 91 and $96 \%(\mathrm{p}<0.05)$, respectively. No significant differences were observed in regard to SHBG (Tables 5, 6). No differences between the beginning and the end of the experimental period were observed in the control group in all hormonal parameters.

\section{DISCUSSION}

Studies in children participating in competitive sports have demonstrated distinct differences in height and body composition ${ }^{23-25}$. Information concerning hormones related to growth and sexual maturation is scanty. ${ }^{9}$

Table 5. Hormonal concentrations of experimental (AG, WG) and control groups (CG) at the beginning (Pre) and at the end (Post) of the experimental period

\begin{tabular}{|c|c|c|c|c|c|c|}
\hline & \multicolumn{2}{|c|}{$\begin{array}{c}\text { AG: } \\
\text { aerobic training group }\end{array}$} & \multicolumn{2}{|c|}{$\begin{array}{c}\text { WG: } \\
\text { resistance training group }\end{array}$} & \multicolumn{2}{|c|}{$\begin{array}{c}\text { CG: } \\
\text { control group }\end{array}$} \\
\hline & Pre & Post & Pre & Post & Pre & Post \\
\hline $\mathrm{T}(\mathrm{nmol} / \mathrm{L})$ & $2.98 \pm 3.58$ & $4.49 \pm 7.5$ & $4.88 \pm 5.75$ & $10.94 \pm 6.26$ & $6.1 \pm 4.45$ & $6.6 \pm 4.05$ \\
\hline $\mathrm{SHBG}(\mathrm{nmol} / \mathrm{L})$ & $54.95 \pm 27.13$ & $58.1 \pm 24.77$ & $69 \pm 30.92$ & $61.5 \pm 42.17$ & $64.2 \pm 21.84$ & $73.7 \pm 25.17$ \\
\hline FAI & $8.1 \pm 12.47$ & $11.17 \pm 19.12$ & $15.6 \pm 26.12$ & $28.49 \pm 33.56$ & $12.75 \pm 15.1$ & $12.1 \pm 13.61$ \\
\hline
\end{tabular}


Table 6. Mean hormonal differences (Post-Pre) of experimental (AG, WG) and control groups (CG), (mean \pm SD)*

\begin{tabular}{lccc}
\hline & $\begin{array}{c}\text { AG } \\
\text { aerobic training group }\end{array}$ & $\begin{array}{c}\text { WG } \\
\text { resistance training group }\end{array}$ & $\begin{array}{c}\text { CG } \\
\text { control group }\end{array}$ \\
\hline $\mathrm{T}(\mathrm{nmol} / \mathrm{L})$ & $+1.39 \pm 4.36$ & $+6.11 \pm 3.83^{*} \dagger$ & $+0.5 \pm 1.10$ \\
$\mathrm{SHBG}(\mathrm{nmol} / \mathrm{L})$ & $+4.10 \pm 13.87$ & $-1.15 \pm 13.95$ & $+9.5 \pm 11.4$ \\
$\mathrm{FAI}$ & $+1.81 \pm 12.22$ & $+12.85 \pm 9.77^{*} \dagger$ & $+0.64 \pm 2.91$ \\
\hline
\end{tabular}

Bonferroni post hoc comparisons $\mathrm{p}<0.05$ : * WG vs $\mathrm{AG}, \uparrow \mathrm{WG}$ vs $\mathrm{CG}$

(Post-Pre): mean differences between the beginning and the end of the experimental design, AG: aerobic training group, WG: weight training group, CG: control group.

Physical exercise is an important factor influencing children body composition ${ }^{1}$; however, the possible differences in BMI among children with different athletic activities require further investigation. Damsgaard et al (2001) failed to demonstrate any significant difference in BMI among boys aged 9-13 years who participated in swimming, tennis, handball and gymnastics. Contrary to these findings, the results of our study revealed clear differences in BMI between basketball players, swimmers and weight-lifters. The differences in BMI and body fat among the groups in our study could be attributed to the criteria with which the children were selected for the particular sports. Among other things, these criteria included physical characteristics related to slightly advanced body development and maturity and to the ideal body shape for the maximization of performance ${ }^{26,27,10}$ taking into account that the influence of exercise on the anthropometric characteristics is not evident in the prepubertal period and is observed in the sex steroid controlled phase of development ${ }^{28}$.

In our study, although the individuals participating in the various groups of athletes were at comparable stages of pubertal development, significant differences were noticed as far as the age, BMI, body fat, FAI, SHBG and GH were concerned. GH in athletes correlated significantly only to T and FAI, without any obvious close relationship to the anthropometric features and age. The group of athletes did not differ from the control group in the variables $\mathrm{T}$ and FAI, which presented significant correlations with age, height, weight and stages of development. There was no correlation among hormonal parameters, age, biological stages and anthropometric features in the control group. The mean values of hormonal parameters in the sample ranged within the normal values of age and $\operatorname{sex}^{22}$.
The hormonal results of our study are in contrast to those of Mero et $\mathrm{al}^{10}$, who, having compared 4 different groups of comparable age athletes (sprinters, long distance runners, strength athletes and control group) did not find any significant differences in $\mathrm{T}$ and $\mathrm{GH}$ between the athletes and the controls and among the groups of athletes, respectively. In their study, T correlated significantly to pubertal development, chronological age and $\mathrm{GH}$ in the athletes group.

The significant differences in T, SHBG, GH mean values among different athletes group of our study could be attributed to the different forms of exercise, and were more obvious in the sports in which the performance is related to muscle mass and strength, such as rowing and handball. The weight-lifters, probably because of their younger age among all groups, had the lowest mean hormonal values. Nevertheless, the nature of this sport might lead to specific exercise related hormonal changes ${ }^{29}$.

The correlations of $\mathrm{T}$ and FAI with the anthropometric variables and the pubertal stages of development in the athletes group compared to the total lack of relevant correlations in the control group indicate that the athletes were under the influence of exerciseinduced anabolic procedures 9 .

Considering the ANOVA results of our study, where age, stages of development and BMI appeared to be taken into account in the effect of different forms of exercise regarding T and SHBG, we are led to conclude that the differences of hormonal parameters among the groups should also be attributed to development and maturity factors ${ }^{30}$. The significant correlations among $\mathrm{T}$, age, development stages and height in the experimental groups of athletes confirm these findings.

The influence of the two-month exercise pro- 
gramme (aerobic and weight training) on the androgens of athletically inactive children (sedentary boys) revealed that the exercise- induced changes in $\mathrm{T}$ and FAI, in the weight training group were considerably greater than those of the aerobically trained and the control group signifying the critical role of the specificity of training in sex hormones indexes. Testosterone and FAI mean differences of WG between the beginning and the end of the training period (pre-post) were significantly larger than those of $A G$ and the controlled, untrained, respectively. There are few data on the influence of aerobic training ${ }^{13}$ and weight-training $^{31}$ on individuals in early-puberty. Specifically, while aerobic training does not seem to have an effect on the anabolic-androgenic process, weight -training increases considerably $\mathrm{T}$ and FAI. This is of particular interest since it is well known that $\mathrm{T}$ during puberty exerts an anabolic action on muscle growth ${ }^{32}$ and is related to the biological condition of the trainees ${ }^{33}$ and FAI, the biologically active or unbound $\mathrm{T}$ (free testosterone) which is available to tissues, and demonstrate the subjects trainability ${ }^{34}$.

A number of points need to be clarified with regards to mechanisms that characterize the exerciseinduced changes in early-pubertal individuals. Firstly, it is possible that the exercise related hormonal adaptations might contribute, as additional stimulus, to the intense anabolic process of growth velocity. Secondly it is well documented that increases in strength after resistance training in early-pubertal subjects are probably caused by modifications in the neuromuscular activation patterns as well as by changes in certain intrinsic characteristics ${ }^{35}$. Finally, the question is raised as to the potential role of $\mathrm{T}$ in strength acquisition influencing neural factors ${ }^{17,36}$ and the possible muscle fiber transition of type II to more glucolytic profiles? ${ }^{37}$

Overall, it appears that the hormonal differences among athletes of different sport groups are partially attributable to the influences of physical exercise. Nevertheless, developmental factors and the selection procedures of athletic talents possessing optimal physical characteristics for these specific sports are by no means insignificant. The participation of children in widely popular sports such as swimming, basket ball, track and field events should be considered as facilitating the developmental process as long as the specific physiological limit of training for the particular age ranges are not violated. The importance of the specificity of training stimulus in the hormonal adaptations during pre-pubertal or early pubertal of athletically inactive children was demonstrated within the limitations and constraints of this study.

\section{ACKNOWLEDGEMENTS}

We would like to thank the participants and their parents for their enthusiastic contribution and patience. We are thankful to Dr. D.A. Adamopoulos, $\mathrm{MD}, \mathrm{PhD}$, Chief Endocrinologist, Helena Venizelos Hospital, for reviewing our manuscript, and to $\mathrm{Mr} \mathrm{K}$. Tsolakis, ex director of Biochemistry Laboratory of, Sotiria Hospital as well the staff of the endocrine laboratory department of Helena Venizelos Hospital for their expert technical assistance.

This study was supported by grants from the Greek State Scholarships Foundation (IKY).

\section{REFERENCES}

1. Malina RM, Bouchard C, 1991 Physical activity as a factor in growth, maturation and performance. Growth, maturation, and physical activity. Human Kinetics, Champaign; I11 pp, 371-390.

2. Theintz GE, Howald H, Weiss U, Sizonenco PC, 1993 Evidence for a reduction of growth potential in adolescent female gymnasts. J Pediatr 122: 306-313.

3. Malina RM, 1994 Physical growth and biological maturation of young athletes. Exerc Sport Sci Rev 22: 389-433.

4. Rogol AD, 1994 Growth at puberty: interaction of androgens and growth hormone. Med Sci Sports Exerc 6: 767-770.

5. Cumming DC, Wheeler GD, McColl EM, 1989 The effects of exercise on reproductive function in men. Sports Med 7: 1-17.

6. Deshenes MR, Kraemer WJ, Maresh CM, Crivello JF, 1991 Exercise induced hormonal changes and their effects upon skeletal muscle tissue. Sports Med 12: 80-93.

7. Van Borselen F, Vos NH, Fry AC, Kraemer WJ, 1992 The role of anaerobic exercise in overtraining. Nat Strength Cond Assoc J 14: 74-79.

8. Hakkinen K, Keskinen KL, Alen M, Komi PV, Kauhanen H, 1989 Serum hormone concentrations during prolonged training in elite endurance trained and strength trained athletes. Eur J Appl Physiol Occup Physiol 59: 233-238.

9. Mero A, Kauhanen H, Peltola E, Vuorimaa T, Komi PV, 1990 Physiological performance capacity in different prepubescent athletic groups. J Sports Med Phys Fitness 30: 57-66.

10. Mero A, Jaakola L, Komi PV, 1990 Serum hormones and physical performance capacity in young boys athletes during a 1 year training period. Eur J Appl Physiol Occup Physiol 60:32-37. 
11. Mero A, Jaakola L, Komi PV, 1989 Neuromuscular, metabolic and hormonal profiles of young tennis players and untrained boys. J Sports Sci 7: 95-100.

12. Fahey TD, Del Valle Zuris A, Oehlsen G, Tried M, Seymour J, 1979 Pubertal stage differences in hormonal and hematological responses to maximal exercise in males. $\mathbf{J}$ Appl Physiol 46: 823-827.

13. Messinis D, Tsolakis C, Stergioulas A, Dessypris A, 2000 Androgen responses following a two-month endurance training program and one month detraining in prepubertal boys. N Zeal J Sports Med 1: 9-12.

14. Rowland TW, Morris AH, Kelleher JF, Haag BL, Reiter EO, 1987 Serum testosterone response to training in adolescent runners. Am J Dis Child 141: 881-883.

15. Rich PA, Villani R, Fulton A, et al, 1992 Serum cortisol concentration and testosterone to cortisol ratio in elite prepubescent male gymnasts during training. Eur J Appl Physiol 65: 399-402.

16. Fry AC, Kraemer WJ, Stone MH, et al, 1993 Endocrine and performance responses to high volume training and amino acid supplementation in elite junior weight-lifters. Int J Sport Nutr 3: 306-322.

17. Tsolakis Ch, Messinins D, Dessipris A, 2003 Strength adaptations and hormonal responses to resistance training and detraining in preadolescent males J Strength Cond Res (in press).

18. Tanner JM, 1962 Growth at Adolescence. UK: Blackwell Scientific Publications, Oxford.

19. Slaughter, MH, Loghman TG, Boileau RA, et al, 1988 Skinfold equations for estimation of body fatness in children and youth. Hum Biol 60: 709-723.

20. Mazes RB, Bisek J, Trempe J, Pouchot S, 1991 Effects of tissue thickness on body composition measurements using dual energy x-ray absorptiometry. WI: Lunar Corporation, Madison.

21. Farmos Ria Diagnostica, 1996 SHBG immunoradiometric assay kit.

22. Tientz RW, 1990 Clinical guide to laboratory tests. Saunders, Philadelfia.

23. Claeesens AL, Veer FM, Stijnen V, et al, 1991 Anthropometric characteristics of outstanding male and female gymnasts. J Sports Med 9: 53-74.

24. Baxter-Jones ADG, Helms PJ, 1996 Effects of training at a young age: A review of the training of young athletes.
(TOYA) study. Pediatric Exercise Science 8: 310-327.

25. Damsgard R, Benke J, Matthiesen G, Petersen JH, Muller J, 2001 Body proportions, body composition and pubertal development of children in competitive sports. 11: 5460.

26. Baxter LA, Helms P, Maffuli N, Baines PJ, Preece M, 1995 Growth and development of male gymnasts, swimmers, soccer and tennis players: a longitudinal study. Ann Hum Biol 22: 381-394.

27. Bajin B 1987 Talent identification program for Canadian female gymnasts In: Petiot B, Salmela JH, Hoshizaki TB (eds) World Identification for Gymnastic Talent, Sports Psyche Editions, Montreal; pp, 34-44.

28. Malina, RM, Bielicki T, 1996 Retrospective longitudinal growth study of boys and girls active in sport. Acta Paediatr 85: 570-576.

29. Blimkie CJR, 1993 Resistence training during preadolescence. Issues and Controversies. Sports Med 15: 389-407.

30. Weimann, E, Blum WF, Witzel C, Schwidergall S, Bohles HJ, 1999 Hypoleptinemia in female and male elite gymnasts. Eur J Clin Invest 29: 853-860.

31. Tsolakis Ch, Messinis D, Stergioulas A, Dessypris A, 2000 Hormonal responses after strength training and detraining in prepubertal and pubertal boys. J Strength Cond Res 14: 399-404.

32. Florini JR, 1985 Hormonal control of muscle cell growth. Muscle and Nerve 10: 577-598.

33. Vermeulen A 1974 Leydig cell secretion in (pre) pubertal boys in delayed puberty In: James V, Serio M, Martini L (eds) The Endocrine function of the human testes, New York: Academic; pp 145-160.

34. Allen M, Pakarinen A, Hakkinen K, Komi PV, 1988 Responses of serum androgenic anabolic and catabolic hormones to prolonged strength training. Int J Spotrs Med 9: 229-233.

35. Blimkie CJR, 1993 Resistance training during preadolescence. Sports Med 15: 389-407.

36. Kraemer WJ, Fry AC, Warren BJ, et al, 1992 Acute hormonal responses in elite junior weightlifters. Int J Sports Med 13: 103-109.

37. Sale DG 1989 Strength training in children In: Gisolfi CV, Lamp DR (eds) Perspectives in Exercise Science and Sports Medicine, Carmel IN: Benchmark Press; pp, 165216. 